\title{
Assessing corrosion mechanisms in Brazilian reinforced concrete bridges: Considerations on inspection procedures and detection techniques
}

Received (in revised form): 28th November 2010

\author{
Líbia da Costa Lourenço \\ is a civil engineer (Fluminense Federal University (UFF), 1985), a specialist in environmental planning (UFF, 1987), \\ and holds an MSc degree (UFF, 2007) and since 1993 has occupied a position as Associate Researcher at UFF. \\ She started her career as a construction manager for some Brazilian companies before entering the academic career. \\ She is currently conducting significant research on structural engineering, with emphasis on deterioration and \\ corrosion in Brazilian reinforced concrete bridges and buildings.
}

\section{João Cassim Jordy}

is a civil engineer (Rio de Janeiro State University (UERJ), 1981), holds MSc (UFF, 2002) and DSc degrees (UFF, 2009) and has experience in construction techniques and structural rehabilitation. From 1999 to 2002, he occupied a position as Assistant Professor at UERJ. Since 2007, he has worked as Associate Researcher at National Institute for Industrial Property (INPI) and is currently investigating issues related to construction maintenance and rehabilitation.

\section{Luiz Carlos Mendes}

is a civil engineer (UFF, 1981), holds MSc (UFF, 1986) and DSc degrees (UFRJ, 1993) and started his academic career as an assistant professor at UFF. Since 1993, he has occupied a position as Associate Professor and principal investigator at UFF, working on issues related to structural analysis and bridge design. More recently, he has joined a new research group to investigate the occurrence of corrosion and other damages in buildings and bridges.

Correspondence: Líbia da Costa Lourenço, Fluminense Federal University, Rua Passo da Pátria, 156 - Bloco D - 30 andar, Niterói, RJ, 22020-010, Brazil

E-mail: libia@vm.uff.br

ABSTRACT This article presents general remarks on concrete bridge inspection, taking Brazilian examples to illustrate the concepts and ideas shown in this work. Brazilian bridges have a special role in the country's viary system, permitting the circulation of products and people. Despite its importance, many Brazilian bridges are not treated correctly when affected by corrosive processes. Many of these structures are built in reinforced concrete, although steel and wood bridges are also found. This work describes the most common damages caused by corrosion in Brazilian reinforced concrete bridges. The most relevant types of corrosion found in Brazilian structures are presented, followed by a discussion of the main inspection methods used for the detection of these corrosive processes, emphasising the importance of visual verifications. The inspection procedures presented are also useful for assessing defects in buildings and other concrete structures. Journal of Building Appraisal (2011) 6, 249-259. doi:10.1057/jba.2011.2

Keywords: corrosion; bridges; concrete structures; construction inspection; Brazilian structures 


\section{INTRODUCTION}

The first notable bridge built in Brazilian territory was inaugurated in 1643 over the Capibaribe River, in the city of Recife. This bridge, built in wood, was part of the city urbanisation project created by the Dutch governor of Recife Maurice of Nassau. The Recife Bridge lasted for 160 years until it collapsed, owing to wood fatigue. A metallic bridge was built in order to replace the former one, but the metallic structure was affected by corrosion and had to be removed. In 1910, the local government constructed a reinforced concrete bridge, called Maurice of Nassau Bridge (Lourenço, 2007). Nowadays, this bridge has periodical inspection processes, in order to avoid structural problems.

Since 1643, many other bridges have been built all over the country. In the middle of the twentieth century, during the Brazilian industrialisation, many automotive industries started the serial production of cars and other automotive vehicles. This production of automobiles demanded the construction of roads and the expansion of the viary network. Between 1950 and 1970, the number of highways increased exponentially in Brazil. In order to expand and optimise the country's viary system, a significant number of reinforced concrete bridges were built in this period.

In the last decades, a great part of the internal circulation of people and products has been based on the road systems, which confers an additional importance to the roads and thus to their bridges. However, many structural damages, especially corrosion, are found in Brazilian reinforced concrete bridges, affecting, in this way, the service life and the capacity of these structures.

Understanding and describing the structural damages and failures that affect reinforced concrete bridges are the first steps to propose recovery methodologies to the affected structures. The case study of corrosion in Brazilian bridges serves as a model for the detection and characterisation of similar damages worldwide. Importantly, the concepts and methodology presented here can be used for the detection of corrosion and related damages in structures other than bridges.

\section{EFFECTS OF CORROSION IN REINFORCED CONCRETE BRIDGES}

The effects of corrosive processes in reinforced concrete structures depend on several factors, which include the structural design, presence of previous structural failures, environmental aggressivity and concrete composition. This complexity is the main reason that impedes the standardisation of the corrosion effects. However, some of the consequences generated by corrosion in reinforced concrete can be pointed, owing to their universal character.

On the basis of which component of the structure is affected, it is possible to distinguish between two principal kinds of corrosion effects in Brazilian reinforced concrete bridges. The first kind includes the damage that has occurred in the cement- and concrete-based structural elements, mainly represented by fissuration and cracks. The second kind is composed of damage that affects the metallic components such as the reinforcement bars and beams.

In Brazilian practice, fissures and cracks are defined as linear fractures on a surface. There is no clear differentiation between them, but it is generally considered that fissures are much thicker and less extensive than cracks (Departamento Nacional de Infraestrutura de Trânsito, 2006).

Fissuration is one of the most common structural damages in concrete bridges worldwide. This mainly originates from an irregular distribution of tension inside the structure, but this damage can also be caused by a chemical reaction between concrete 


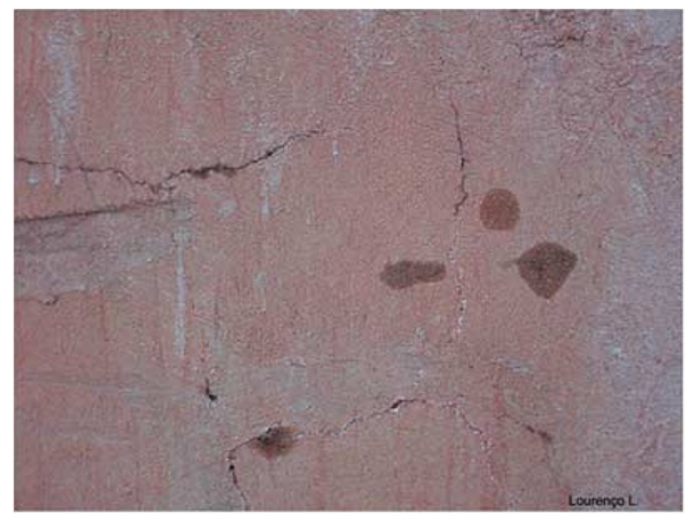

Figure I: $\quad$ Fissures in bridge column in Pará, Brazil.

components and external reagents or by concrete disaggregation. The latter two factors are characterised as corrosive processes.

Fissures occur much more often than the cracks in Brazilian structures, which does not reduce the importance of the latter. The existence of cracks may lead to irreversible defects, such as load resistance decrease and structural disequilibrium.

The structural damage presented by bridges and other structures originates not only from lack of maintenance, but also from environmental conditions. The fissuration phenomenon in Brazilian structures is one type of damage that is caused by both factors, which explains the major concentration of cases in urban areas.

In addition to the fact that urban areas have higher $\mathrm{CO}_{2}$ levels, environmental variables, such as temperature, wind, rain incidence and air humidity, can make these sites more precarious for concrete structures.

The bridge over Tocantins River (Figure 1) is located in a mining- and industrial-based city. These economic activities are the main sources of the environmental aggressivity found in this region. Some climatic characteristics, such as the high incidence of sunrays, also contribute to the structural deterioration, although they are not frequently associated with fissuration.

The internal environment of a reinforced concrete structure is strongly alkaline, with a $\mathrm{pH}$ level close to 12 . This alkalinity is caused mainly by concrete hydration, which forms a calcium hydroxide solution in the structure. The penetration of aggressive substances in the concrete, allowed by fissuration and concrete disaggregation, reduces the local $\mathrm{pH}$, permitting, in this way, the beginning of corrosive processes in that environment.

Reinforcement bars are naturally protected by an inert and thin oxide layer, which reduces metallic deterioration. The passivation layer, as it is known, presents high electrical stability, low ionic conductivity and low solubility - three important characteristics that help prevent corrosion. However, when concrete alkalinity is reduced and aggressive components penetrate the structure, the passivation layer is normally destroyed, which exposes the metallic bars to corrosion (Figure 2).

The main evidence of deteriorating processes in reinforcing bars includes the loss of cross-sectional area and the emergence of oxide stains, originating from corrosion products. Basically, the detection of these evidences depends on a visual inspection, the importance and limitations of which will be discussed later.

In most cases, the appearance of iron-oxide stains is associated with the exposure of reinforcement bars (Figure 3). This can be explained by the high environmental 


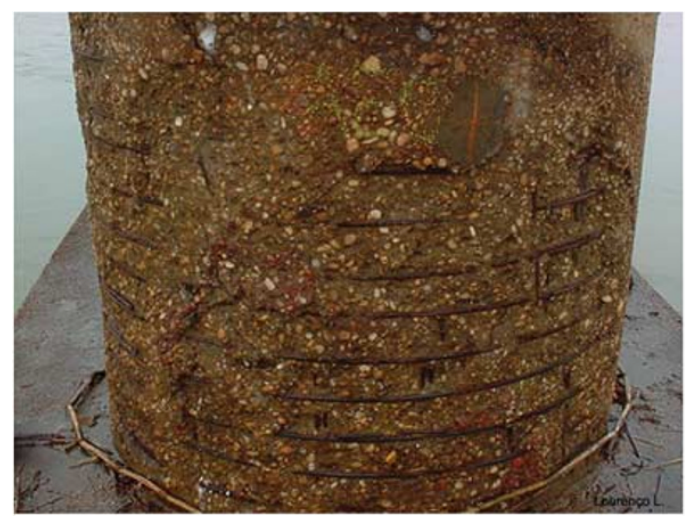

Figure 2: Rebar exposure in bridge column in Pará, Brazil.

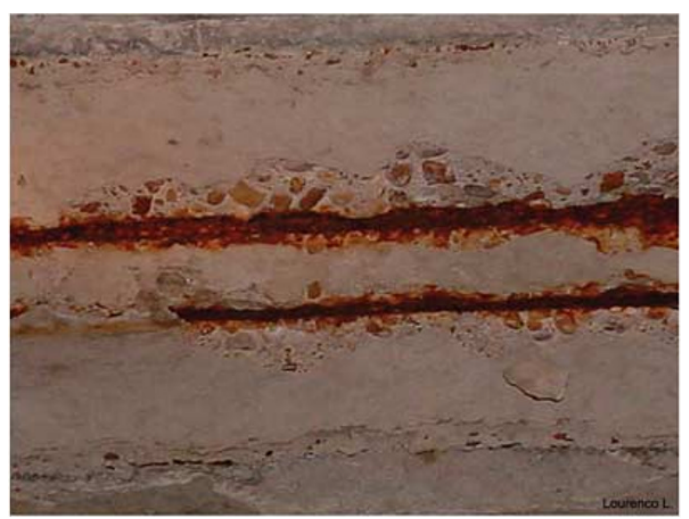

Figure 3: Rebar exposure associated with iron-oxide stains.

aggressivity rates found in places near bridges and viaducts, which induce concrete deterioration and fasten corrosion development.

However, in some situations, these stains appear in non-deteriorated concretes, suggesting an internal aggressive microenvironment. The evaluation of damage extension and its relevance to the structural behaviour should be provided by localised invasive tests.

\section{CORROSION MECHANISMS IN REINFORCED CONCRETE BRIDGES}

As previously reported here, aggressive environments are responsible for most cases of corrosion in reinforced concrete structures (Figure 4). This environmentally damaging action is observed through many different mechanisms that need to be completely described and understood. Here, two of the most common corrosion mechanisms are presented: chloride action and carbonation. They are the best-known processes, although some aspects remain unclear.

The damaging action of chloride is very well described in the specialised literature. It is a consensus among authors and professionals that chloride ions start corrosive processes in reinforcement bars and also in cement, increasing corrosion effects in the structure. In addition, the beginning of chloride-induced corrosion is not always recognised unless there is a periodic monitoring of chloride rates. These are the reasons 


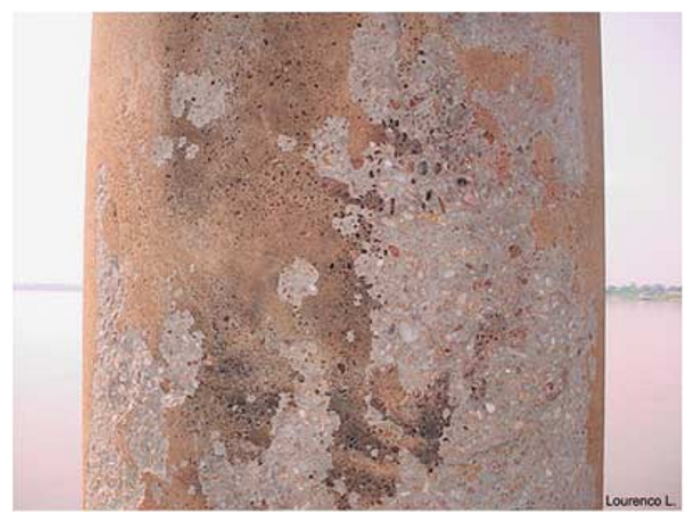

Figure 4: Pathological damages on bridge column in Pará, Brazil.

that make this kind of corrosion one of the most serious pathologies suffered by the structures.

The first relevant question in the chloride action analysis is how these ions reach the structure. The presence of chloride in the structure is due to the concrete composition and preparation, or to external ionic transportation. Concrete preparation involves the addition of many substances, some of which include chloride and other chlorine compounds, such as impure aggregates (Figueiredo, 2005).

The penetration of external ions in the structure is another important way of increasing chloride rates inside the structure. Many factors are directly related to the capacity of ionic penetration in concrete. Some of them are: physical properties of the dominant fluid; concrete composition and porosity; gradient and potential differences and chemical balance of chloride forms.

Fluid characteristics, such as viscosity and surface tension, and electric differences are regulatory factors to the ionic permeability and to the diffusion rates in a concrete-environment interface. However, the most important role in chloride penetration is played by concrete porosity, whose variables control the ionic absorption, concentration and kinetics. Some authors classify concrete blocks as false solids, because of porosity and its capacity to change the materials properties (Rodrigues, 2001).

A precise determination of the relation between ionic transportation and concrete porosity in a structure must include the evaluation and characterisation of the pores, according to the following parameters: density, extension, interconnections, diameter and origin. This analysis, associated with chemical tests, allows to establish a reliable physical model of chloride transportation in a structure. Strong efforts have been made in order to design, develop and improve the chloride penetration models and sensors in the last decade.

In addition to the complex mechanism of ionic transportation into concrete, it is noteworthy that high chloride concentration in the air/water near the structure is an essential condition to start the transportation and, consequently, the corrosive process. Even though there is a minimum reactive concentration to initiate the structural deterioration, this level can be easily reached in some environments.

Brazilian bridges are especially subject to this kind of corrosion and all its mechanisms, considering that most of them are located in aggressive environments.

Although the effects of chloride-induced corrosion are well known and described, the chemical interactions that cause this kind of corrosion are still not clear. There are three 
current theories to explain the role of chloride ions in deteriorating the metallic structural elements. All theories suggest that there are localised concentrations of chloride ions (Wheat et al, 1996), leading to pitting corrosion in reinforcement bars.

The first of them, called oxide film theory, indicates that chloride ions easily penetrate the passivation layer, owing to its low molecular weight. The easy penetration promotes an ionic dispersal over the surface, allowing a later interaction with the metallic bars.

Another explanation, named adsorption theory, suggests that chloride competes with hydroxide ions and with dissolved oxygen to be adsorbed by the iron-oxide layer. When adsorbed, chloride promotes the hydration of metallic ions, making their liberation easier.

The transitory complex theory postulates that there is a competition between chloride and hydroxide ions to form iron compounds through an electrochemical mechanism. These compounds are mainly soluble iron chloride complexes, the diffusion of which causes the passivation layer destruction.

Although there is no consensus about the chemical mechanism that induces deterioration in reinforcement bars, the corrosive action of chloride ions can be characterised as a disorganisation of the passivation layer that exposes the reinforcing bars to the direct action of aggressive substances. The first step of this process is the penetration and accumulation of chloride ions in the structure, creating an aggressive microenvironment. This is followed by localised depassivation, and thereafter pitting corrosion in the reinforcement structure.

Carbonation is a natural process that consists of the reduction in alkalinity of concrete surfaces. It occurs through a carbonate-formation reaction between calcium hydroxide and environmental reagents, such as $\mathrm{CO}_{2}$ and $\mathrm{SO}_{2}$. Consequently, the concrete structure becomes more fragile and allows an increase in the penetration of aggressive elements.

In general, carbonation is a multi-step process that reduces the average $\mathrm{pH}$ from values around 12.5 to values under 9.4. The exact value at which the corrosive process starts is still not established, although some authors have described a depassivation profile in $\mathrm{pH}$ values close to 11.5 .

As chloride action, the beginning of a carbonation process has no characteristic symptomatology detected by visual inspection. However, in some cases, it is possible to recognise surface whitening and small points or thin white lines over concrete surface. In more advanced stages, carbonation may be evidenced by large areas of white and disaggregated concrete. Nevertheless, great number of cases show no clear evidence.

It is also noteworthy that a structure may present different stages of carbonation, according to local aggressivity and structural design. Aquatic environments have a lower capacity of $\mathrm{CO}_{2}$ diffusion in comparison with air, so that carbonation rates are higher in the latter.

An important feature of carbonation is the occurrence of carbonation fronts, which represent the interface between carbonated and non-carbonated areas. Carbonated areas are characterised by the predominance of $\mathrm{CaCO}_{3}$ among calcium compounds. Other calcium salts are also found in lower concentrations. In a normal carbonation process, carbonated concrete undergoes a slight reduction in volume, known as carbonation shrinkage, the intensity of which will depend on air humidity and temperature. On the other hand, reinforcement corrosion mechanisms may generate an expansion in concrete, resulting in the exposure of reinforcement bars, allowing the depassivation and increased corrosion of these elements. 
Although both are involved in the development of corrosive processes, chloride and carbonation action are very distinct from each other in their origin and mechanism of action. However, it has been suggested that an integrated action between these two distinct mechanisms plays a very important role in concrete deterioration (Bakker, 1988). Comparative approaches demonstrate that the combination of chloride contamination and carbonation results in a stronger and faster corrosive process than the ones generated by each form individually (Roper and Baweja, 1991). Depending on the intensity of each process, the association of both may lead to the most severe corrosion effects in a structure.

The integrated action concept becomes appropriate when applied to Brazilian structures, in many of which carbonation and chloride symptoms are often found acting together in the deterioration process. This is the reason that had made this idea a novel approach in Brazilian specialised literature.

\section{CONSIDERATIONS ON BRIDGE INSPECTION}

As previously seen, reinforced concrete bridges are exposed to various mechanisms of deterioration, some of which are not completely described and understood. The best-known ones, carbonation and chloride action, have been described as the most common and powerful corrosive processes in reinforced concrete structures. Some care is needed to avoid the occurrence of damage caused by deterioration mechanisms, to maintain the functionality of the structure and to enlarge its service life.

This care should be represented by an effective maintenance project, covering all procedures to provide optimal bridge conditions. However, in many cases, maintenance processes are not adequate to prevent the existence of severe pathological problems in bridge structures. In these situations, an urgent recovery is needed to restore their functionality.

In this context, the importance of bridge inspection procedures as a contributor to good structural conditions has emerged. These inspections are necessary to decide about any alteration or improvement in a structure, expected or not. They should also be repeated periodically in order to diagnose emerging problems and propose corrective mechanisms.

According to Brazilian normatisation, five main types of bridge inspection can be distinguished: registering, routine, extraordinary, special and intermediate (Departamento Nacional de Infraestrutura de Trânsito, 2004). Architectural design and the incidence of pathologies will determine the type of inspection needed and its periodicity.

Registering inspection is the first inspection to be made after a bridge is built or after a big reform in a pre-existing structure, when project elements and supervision details are still available. The registering report, finished after all procedures, must be as complete as possible, considering that this report will be a reference to all subsequent inspections of that bridge. The detection of damage and failures that may affect the structure functionality, or its safety, indicates the need of a special inspection.

Routine inspection is periodic and occurs biannually in most Brazilian cases. Bridges situated in very aggressive environments or with bad structural conditions may need more frequent inspections. This procedure includes the visual observation of failures and defects and the description of any modifications made in the last interval between inspections.

Extraordinary inspection is an unexpected procedure to describe and evaluate the occurrence of exceptional damages caused by man or by nature. In these cases, intervention measures have to be proposed and further recovery procedures should be defined. 
Special inspection consists of a detailed visual verification accompanied by field or lab structural tests and measurements. High structural complexity and the detection of bridge failures in previous reports are the basic reasons to perform this kind of inspection. Intermediate inspection is a way of investigating and monitoring the effects of recent-developed structural types and novel recovery methodologies applied to a structure.

Inspections in reinforced concrete bridges must consider the concepts related to the materials used in the structure. The service life of each material and durability of the structure, associated with the maintenance processes planned in the project, form the basis for the assessment of bridge pathologies. This analysis should include the identification of deterioration form and an evaluation of both quantitative and qualitative factors involved in the corrosive process.

In this respect, the visual analysis represents one of the most important steps to determine the type and extent of damages and failures. It allows the recognition of symptomatology presented by the structure, which represents the clearest signs of deterioration. This deterioration acquires a wide sense, corresponding not only to the corrosive process itself, but to its damaging effects. It means that visual inspection plays an important role in the global inspection process, influencing the decisions about which specific tests should be conducted.

Although Brazilian normatisation does not emphasise the visual verifications needed in a bridge structure, specialised literature and engineering practice provide a list with some relevant aspects to be observed in a bridge structure (Cascudo, 1997), such as rebar exposure, loss of adherence between concrete and bars, ocher-like stains over concrete surface and so on.

A survey presented in 2001 by the American government shows that visual inspection is the most used technique to evaluate the extent of damage in US highway bridges (Moore et al, 2001). Other non-destructive techniques (NDT) were also considered for that survey, although no NDT reached the visual inspection percentage of use. However, it is important to point out that many NDT are extremely relevant to the precise description of pathologic damage observed (Figure 5).

Although no statistical study concerning the main inspection methods used in Brazilian bridges has been made so far, it is possible to infer that Brazilian results would be similar to American ones, considering the previously reported importance of visual inspection of Brazilian bridges. Some NDT, such as ultrasonic and electrochemical tests, would also be relevant in a Brazilian survey.

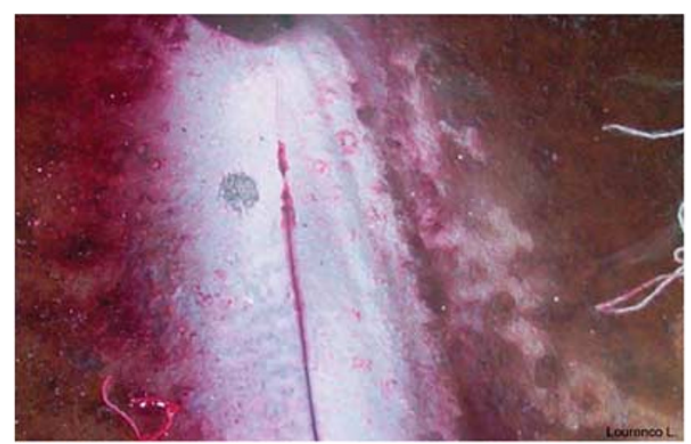

Figure 5: Penetrating liquid test in metallic component of a bridge. 


\section{CONSIDERATIONS ON BUILDING INSPECTION}

Buildings may also suffer strong corrosive processes, the physicochemical mechanisms of which are quite similar to bridge deterioration. However, each structure has its particularities that should be noted. For example, bridges and viaducts are subject to dynamic loads that accelerate deterioration (Mendes, 2003), whereas building corrosion is particularly interesting because of its high dependence on the rate of misuse.

Although bridges and buildings are different structures, regarding design, construction and maintenance, some inspection procedures and damage identification techniques may be used in both types of structure. The differences observed between these two types of structure require that the interpretation of structural data obtained from both be precise.

For example, a frequent failure that is found both in building and in bridges is initialphase carbonation, and thus the intensity this process will acquire depends on various factors. One can find the same shrinkage profile in both structures and will diagnose it as if there were a common origin. However, this is not always true. One cannot generalise and establish a single origin of damaging features in different structures.

In general, the first procedure that should be applied in a building inspection is a visual verification. This inspection is very useful to detect great alterations in the structural condition and to infer eventual localised damages, which means that it will guide the next steps and the final diagnosis. It is noteworthy that NDTs should be implemented when demanded. According to Brazilian practice, visual inspections are often used as the unique procedure to diagnose corrosion in buildings. This is not recommended, as it is not possible to properly understand the course and the nature of a corrosive process.

\section{DISCUSSION}

It is important to emphasise the need for visual verifications in a bridge inspection process. As previously described, these verifications are responsible not only for the formation of a global pathological guide in a structure, but for the correlation between the damages found and the structural design. In this way, visual inspection can be described as a key procedure, contributing to bridge assessment and documenting relevant information about the structure.

Generally, the production of photographic documenting is suggested as a visual inspection result. These photographs may provide an extensive source of information that was not noticed during structure visualisation.

However, despite all advantages, visual inspection has its limitations, reflected by the impossibility of detecting precisely the extent of damage, failures. Some measures cannot be obtained just by visual observation of the structure, such as carbonation and fatigue evaluation. Another limitation consists of the infeasibility of verification in inaccessible areas of bridge structures. In these cases, verifications should be replaced by the use of appropriate equipments or indirect measurements.

Although visual verification is an ordinary procedure in a bridge inspection, it should not be standardised. Each structure has its specificities, which must be considered in an inspection process. In this way, experience exchanges among engineers must be incentivised, mainly by practice and technical reports and by case studies.

Some procedures are required to determine the limitations of visual inspection, permitting the access to deterioration process, since its initiation to its propagation. Simple techniques that are often applied to inspections are considered basic, whereas more complex and, consequently, uncommon ones are considered auxiliary techniques. This distinction is possible because of the efficacy of the basic techniques, which produce sufficient results in most cases, dispensing the use of other techniques. 
In reinforced concrete structures, the most common set of basic techniques (Figure 5) includes ultrasonic tests, $\mathrm{pH}$ variation, hammering and electrochemical tests. Unlike the basic ones, there is no universal normatisation to auxiliary techniques, because of their strict character and regional application. Many of the recent auxiliary mechanisms have been developed in research centres and technological institutions and have specific purposes.

How many and which tests will be administered in a bridge structure depend on several factors unique to each analysed bridge. However, it is important to consider the size of the construction and a preliminary observation of damage extension. These data will indicate the necessary test depth and will also point out the representative zone criteria.

Engineers must be very careful in interpreting the results obtained from structural tests. A range of statistical parameters, such as equipment-related error and sample space, should be considered in data analysis, principally in electrochemical measures where physical quantities express low values and coefficients.

The prior objective of an inspection process is to contribute to the maintenance of the integrity and the functional conditions of a structure. In this way, verifications and tests should be carried out to provide mainly essential data, which will be relevant to bridge recovery. Practical experience shows that verifications covering the conditions of bridge footings, columns, expansion joints and connection elements are indispensable in any inspection process.

\section{CONCLUSIONS}

Bridges are subject to various mechanisms of deterioration, which reduces their service life and functional capacity. A regular inspection programme is needed to prevent and detect corrosive processes and other deterioration forms. Many of these pathological incidences would be avoided if the knowledge of Structural Pathology were properly applied as a prevention measure.

Brazilian reinforced concrete bridges are mainly affected by corrosive processes generated by carbonation and chloride action. A current approach suggests an integrated action between both mechanisms, responsible for the potentialisation of corrosion effects. Although some aspects of corrosion mechanism remain unclear, this approach seems to be very satisfactory when applied to Brazilian bridge structures.

Brazilian buildings may also suffer strong corrosive processes, originating from different sources, which are related to environmental conditions, proper use, project and design. In order to detect corrosion in these structures, a complete inspection process is required. This should include efficient visual verifications, to allow understanding and localisation of observed damages, and also NDT to assess the structural conditions. Therefore, the global process is quite similar to bridge inspection, although focus and data interpretation should differ.

In this context, inspection programmes should emphasise aspects related to the structural integrity and functional capacity maintenance of bridges and buildings. The integration between the visual verifications and other techniques, considering statistical analysis, is the basic methodology to obtain reliable data and to propose a recovery process.

\section{REFERENCES}

Bakker, R.F.M. (1988) Initiation period. In: P. Schiessl (ed.) Corrosion of Steel in Concrete. New York: Chapman and Hall, pp. 22-54. 
Cascudo, O. (1997) O controle da Corrosão de Armaduras em Concreto - Inspeção e Técnicas Eletroquímicas. Goiânia, Brazil: UFG Press.

Departamento Nacional de Infraestrutura de Trânsito. (2004) Inspeções em Pontes e Viadutos de Concreto Armado e Protendido - Procedimento. Norma 010/2004 PRO. Brasília: DNIT.

Departamento Nacional de Infraestrutura de Trânsito. (2006) Tratamento de Trincas e Fissuras - Especificação de Serviço. Norma 083/2006 ES. Brasília: DNIT.

Figueiredo, E.P. (2005) Efeitos da carbonatação e de cloretos no concreto. In: IBRACON (ed.) Concreto: Ensino, Pesquisa e Realizações. São Paulo, Brazil: Ed. IBRACON.

Lourenço, L.C. (2007) Análise da corrosão em estruturas de pontes metálicas e de concreto armado. MSc thesis, Fluminense Federal University, Niterói, Brazil.

Mendes, L.C. (2003) Pontes. Niterói, Brazil: Editora UFF.

Moore, M., Rolander, D., Graybeal, B., Phares, B. and Washer, G. (2001) Highway Bridge Inspection: State-of-thePractice Survey. Virginia: Federal Highway Administration. RD 01-033.

Rodrigues, J. (2001) Bom concreto (armado) versus corrosão. Revista Recuperar 44(1): 21-22.

Roper, H. and Baweja, D. (1991) Carbonation-chloride interactions and their influence to corrosion rates of steel in concrete. ACI Special Publication 126: 295-316.

Wheat, H.G., Kasthurirangan, J. and Kitowski, C.J. (1996) Behaviour of steel in simulated concrete solutions. In: K.L. Scrivener and J.F. Young (eds.) Mechanisms of Chemical Degradation of Cement-based Systems. London: Chapman and Hall, pp. 143-150. 